Another classical concept in agriculture is the role of farm-yard manure in maintaining and increasing soil fertility. Again, farm experience would leave little doubt as to its value, but the reasons for this may not be those we have always assumed. The Chemistry Department has continued its experiments to show just how farm-yard manure affects crops, and an interesting and essential development is a study of liquid manures resulting from the intensive methods of stock management now being practised. Liquids from piggeries were analysed and shown to be rich sources of N.P.K., for example 1,000 gal. of one sample supplied $90 \mathrm{lb}$. nitrogen, $70 \mathrm{lb}$. phosphorus pentoxide and $70 \mathrm{lb}$. potassium monoxide. The disposal of large volumes of such material is a major practical problem on farms to-day, but its value is such that new methods of conservation and disposal must be devised so that this potentially rich source of plant nutrients may be used to full advantage.

The work being carried out by the Botany Depart. ment is concerned with matters ultimately related to crop yields. The physiology and distribution of weed seeds and the competitive activities of the resultant plants have been studied, while the long-term investigations on the physiology of growth and yield continue to provide useful information. One of the major advances in post-war agriculture has been the development of spring varieties of wheat almost the equal in performance to their winter counterparts. An analysis of the photosynthetic processes in varieties of wheat suggested that the greater efficiency of grain production in Capelle and Jufy I was attributable to increased photosynthesis in the ears of these varieties as compared with Squareheads Master or Atle. Studies such as these provide the plant breeder with vital information that may well open up new lines of cereal development. Two new records are reported from the Plant Pathology Department. For the first time blight lesions have been found on a potato tuber without any sign of the disease appearing above ground on the parent or neighbouring plants. This adds to our scanty knowledge of what actually happens in the earliest stages in the development of this well-known disease. For the first time, too, Pithomyces chartarum, the mould responsible for facial eczema in sheep in New Zealand, has been found in several areas in the Home Counties. In New Zealand the disease is a serious one, the organism being produced in enormous quantities, especially on mown grass. The discovery of the fungus in Britain is a direct, if unwelcome, consequence of the utilization of aerial spore-trapping procedures developed at Rothamsted.

Rothamsted does not restrict its services to agriculturo in Great Britain. Overseas problems are studied: the report lists the advisory visits, and secondments abroad, of members of staff. Of interest in this connexion is the work of the Biochemistry Department in devising and establishing leaf protein production units for use overseas. At home the Dunholme Field Station is now closed, and the sugar beet work will be carried on from a new base, Broom's Barn. It is to be hoped that Dr. R. Full and his staff will there find increased scope to continue the excellent and valuable work that has meant so much to the beet industry in Britain.

J. H. WESTERN

\title{
CALCIUM REQUIREMENTS BY HUMAN BEINGS
}

$\mathrm{M}$ ORE people fail to receive the amounts of calcium normally recommended as necessary than of any other nutrient; yet there is little convincing evidence of any disabilities specifically attributable to deficiency of calcium. In many parts of the world only limited opportunities exist for the intake of the recommended amounts, and this has led to suggestions for the widespread fortification of foods with calcium. This can be both expensive and technically difficult, and in the long run-according to a joint Food and Agriculture Organization/World Health Organization Expert Group on Calcium Requirements - nutritional improvements ought to bo met through a better basic diet and not only by supplementation of this kind (WHO Chronicle, 16, No. 7, July, 1962).

No supplementary calcium should be given without first obtaining reliable information about the calcium needs of different population groups. Contrary to what has sometimes been believed, the development of rickets and dental caries is largely independent of the intake of calcium. In adult life no clear signs of calcium deficiency in men have ever been described in any part of the world. In women, among populations where the intake of calcium is habitually low, repeated pregnancies and long lactations may be associated in some regions with the development of osteomalacia, though this is not solely due to the low intake of calcium. In some parts of northern India, for example, osteomalacia is frequent with higher intakes of calcium, whereas it is rare in southern India, where the intake is lower. It would seem that if the intake of vitamin $\mathrm{D}$ is satisfactory, osteomalacia is not a problem even for women whose intake of calcium is low-though a low intake of calcium may be an exacerbating factor. The common osteoporosis of old age is thought by some investigators to be associated with calcium deficiency but by others to be more related to endocrine disturbances. Nor does present knowledge support the view that a low intake of calcium is necessarily prejudicial to normal physiological function, although certain pathological conditions, mostly rare, do exist in which increased intake of calcium may be advisable. Among conditions in which calcium deficiency may play a part are the osteopathy of premature infants; various syndromes involving subnormal calcium absorption, such as steatorrhoea and certain forms of chronic renal damage with or without calciuria, and senile osteoporosis.

In making recommendations on calcium needs, the Expert Group defined the minimum requirement of calcium for adults as the smallest amount that will maintain health and keep the body in calcium balance when the diet is otherwise adequate and the vitamin $\mathrm{D}$ status is satisfactory. The available evidence, however, does not permit the specification of any particular figures for minimum adult requirements; for disorders often attributed to calcium deficiency have not been observed in large populations habitually subsisting on intakes of only $300-400 \mathrm{mg}$ a day, and it has been shown that adults can successfully adapt themselves to intakes of $400-500 \mathrm{mg}$ and even less. 